\title{
FLUXO E INFLUXO: O SONHO NACIONAL BRASILEIRO EM VISTA DO PENSAMENTO EUROPEU
}

Marcelo Chiaretto Universidade Federal de Minas Gerais

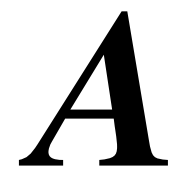

priori parece pouco instigante voltar-se aos temas determinados pelas relações culturais entre Brasil e Portugal, assim como àqueles determinados pela complexa busca da ex-colônia com a finalidade de estabelecer um pensamento autônomo e interessante. De fato, tais temas são contemplados por intelectuais brasileiros e portugueses há pelo menos dois séculos. Entretanto, é inegável o fato de que há ainda variados aspectos a serem investigados, aptos a provocar estudos geradores de oportunas redescobertas.

No que concerne ao séc. XIX, talvez o que melhor caracteriza a história das relações existentes entre os dois países supramencionados, convém examinar certa produção literato-naturalista que representou um papel fundamental no processo de fundação da nação brasileira e na conseqüente aversão à toda ascendência portuguesa. De certa forma, como se imaginou um sonho nacional brasileiro sem a participação de um pensamento português? Da mesma maneira, pode-se questionar: qual a atuação francesa em tal processo de estabelecimento de um pensamento autônomo no Brasil?

\section{Laços nacionais para um mundo novo}

Se a Europa, na passagem do século XVIII para o XIX, discutia sobre como remodelar seus Estados tendo em vista um nacionalismo de cunho político-social ou de cunho místico-natural, o então 
denominado "Novo Mundo" de fato ainda batalhava por se compreender enquanto coletividades ou grupos representativos em busca da transição para um futuro sonho de nação. Segundo Rouanet, por ser exterior - ou melhor, marginal - a essa Europa civilizada, o Novo Mundo está presente há mais de dois séculos nos relatos dos viajantes, o que lhe possibilita desempenhar uma dupla função: "a de fornecer elementos para a consolidação do sistema de pensamento que se está formando, e a de servir de campo de provas para as doutrinas setecentistas do homem e da sociedade". ${ }^{1}$

Bem entendido, antes dos países do Novo Mundo optarem pela formação nacional mais conveniente para suas determinadas situações, pode-se pensar que houve uma espécie de prescrição superior a indicar o melhor caminho a ser seguido. Assim, enquanto a forma nórdica mantinha-se isolada, negando o cosmopolitismo e valorizando a luta interna das culturas em vista de seu verdadeiro espírito nacional; os iluministas, por outro lado, traziam os mundos exóticos e as culturas desconhecidas para o foco de seus estudos com a finalidade de experimentar as técnicas que caracterizavam o plano de irradiação da cultura e da civilização modernas pelo mundo. ${ }^{2}$

É lícito dizer que o Novo Mundo americano foi descoberto em livros compostos por viajantes na maioria das vezes deslumbrados pela possibilidade de se concretizar o paraíso celeste nos trópicos. ${ }^{3}$ Diante de tais narrativas e consoante seus modelos de pesquisa, os pensadores iluministas acabaram por concluir pela existência de uma sociedade paradisíaca, sem história, "sem fé, rei ou lei", já que o clima da América isso indicava:

As primeiras narrativas de viagens, com o seu entusiasmo ingênuo pelos selvagens, a sua admiração pela vida simples dessas povoações do novo Mundo que viviam sem padres, sem leis e sem reis, e

${ }^{1}$ Cf. ROUANET, 1991. p.59.

${ }^{2}$ Dentre esses estudos, convém destacar o Essai sur les moeurs de Voltaire e as Lettres persanes de Montesquieu.

${ }^{3}$ Cf. referências a NAVARRETE em BUARQUE apud ROUANET, 1991. p.56. 
principalmente que não conheciam "nem teu nem meu", pareciam já anunciar as mais ousadas teorias de Rousseau. ${ }^{4}$

Tudo parecia atestar a presença de "nobres selvagens" em "estado de natureza" - conforme os preceitos de Rousseau - a povoar as terras do inóspito e sedutor Novo Mundo. Diderot, em um raciocínio aparentemente apoiado nos dizeres relacionados acima citados do livro Histoire et description générale de la NouvelleFrance, publicado em 1744 pelo Padre Pierre de Charlevoix, parece confirmar o sonho prestes a ser realizado:

Querem que eu lhes diga um belo paradoxo? É que estou convencido (...) de que só pode haver verdadeira felicidade para a espécie humana em um estado social onde não haja nem rei, nem magistrado, nem padre, nem leis, nem teu, nem meu, nem propriedade mobiliária, nem vícios, nem virtude. ${ }^{5}$

Vê-se dessa forma que a Europa, representada pelo pensamento modernizador que melhor a retratava, expõe a sua ambição de introduzir naquelas paradisíacas terras uma educação para aqueles que se demonstravam ainda desinformados sobre as conquistas e as potencialidades do pensamento racional e da civilização ocidental. Seria uma forma de capacitar todos a encontrar o progresso científico e social, algo mais compreensível - ou mais digno - na perspectiva do olhar europeu, possibilitando o surgimento de verdadeiros homens, uma vez que "o que diferencia o homem do animal é a civilização".

Com efeito, não será buscado aqui salientar a importância política e econômica de todo esse processo para os Estados nacionais europeus. Isso estaria na realidade diretamente relacionado com os nacionalismos a fomentar embates e superações, considerando-se as violentas disputas por territórios e as conquistas daí advindas. $\mathrm{O}$ que se firma neste momento mais interessante é perceber que o modelo civilizacional moderno, divulgado universalmente como o

\footnotetext{
${ }^{4}$ CHINARD apud ROUANET, 1991. p.70.

${ }^{5}$ DIDEROT apud ROUANET, 1991. p.71.

${ }^{6}$ DUVIOLS apud ROUANET, 1991. p.62.
} 
mais apto para as nações que se acham "atrasadas" culturalmente, traria consigo um estilo de formação nacional. Seria algo extremamente conveniente e grandemente sonhado na América de precoce vida político-cultural e institucional.

De fato, o problema então seria compreender como isso se realiza e é neste momento que se observa a importância fundamental do romantismo. Pode-se questionar como um movimento literatopolítico-cultural propugnado em terras brasileiras por estrangeiros logrou corroborar a ideologia oficial ao fundamentar o indianismo na simbologia nacional. Um indianismo, é bom mencionar, firmado na esperança de plasmar um pensamento que fosse de expressão nacional ao mesmo tempo que manifestação de um explícito repúdio em vista de tudo que lembrasse a metrópole portuguesa.

\section{Denis ou "a juventude de um povo como Gênio Nacional"}

No início do séc. XIX, já se afirmou que o Brasil lutava em seus impulsos por descobrir as trilhas que o levassem à emancipação política, a uma conformação identitária, em suma, à sua fundação enquanto nação. Nesse processo, é reconhecida a participação primordial do crítico francês Ferdinand Denis, uma vez que ele pode ser visto como um dos grandes ideólogos - senão o maior - do nacionalismo romântico brasileiro. Para Candido:

Em 1824, [Ferdinand Denis] ilustra as teses de Chateaubriand e Madame de Staël, segundo uma orientação inspirada por Humboldt, em Scènes de la nature sous les tropiques, descrevendo romanticamente a nossa natureza como fonte de inspiração e criando, de certo modo, o nosso indianismo romântico, no conto sobre os Machacalis (...). Mas é em 1826 que junta o Resumo da História literária do Brasil ao Resumo da História Literária de Portugal, fundando a teoria da nossa literatura segundo os moldes românticos, num sentido que a orientaria por meio século e iria repercutir quase até os nossos dias.?

7 CANDIDO, 1993. Tomo II, p.288. 
Candido lembra fatos fundamentais relacionados a Denis, como a prescrição aos escritores brasileiros de uma literatura que buscasse a descrição "romântica" da natureza brasileira - em um enfoque marcadamente mítico segundo o modelo romântico francês -, a imposição de um estilo nativista segundo suas idéias indianistas (indicando a primeira imagem nacional ao Brasil) e a fundação da teoria da literatura brasileira nos moldes românticos em um amálgama a mesclar franceses e alemães, em detrimento de uma reflexão mais "portuguesa".

Em obras como Scènes de la Nature sous les Tropiques, et de leur Influence sur la Poésie, suivies de Camões et Jozé Indiơ - publicada em 1824 , contendo a narrativa "Os Maxacalis" já indicada como texto precursor do romance indianista na literatura brasileira - e no Résumé de l'Histoire Littéraire du Portugal, suivi du Résumé de l'Histoire Littéraire du Brésil,' Denis dará as diretrizes para a formação nacional brasileira. Nesse aspecto ele acabará por possibilitar a fundação de um movimento - o romântico - e, ao mesmo tempo, de uma literatura, em termos definitivamente diferenciadores da metrópole portuguesa.

Com efeito, pode-se dizer também que Denis acabou por iniciar uma produção historiográfica sobre a literatura - e fatalmente sobre a cultura - brasileiras. Para tanto, vê-se que ele teve por base um calculado entusiasmo, seja com a observação de hábitos e costumes estranhos, seja com a percepção de uma natureza exuberante. Denis consolidou assim uma visão interessada do primitivo e do rude, situados em disputa de espaço com uma incipiente "civilização" conforme os moldes europeus, é bom destacar. Seu suporte seria assim as concepções nacionalistas então em voga na Europa dos fins do século XVIII e início do séc. XIX, relacionando a busca do Gênio Nacional a uma concepção da nação como retrato do povo, aliadas à valorização do fator nativista.

${ }^{8}$ DENIS, 1824. In: CESAR, 1978.

${ }^{9}$ DENIS, 1826. In: CESAR, 1978. 
Levando-se em conta a importância fundamental de Ferdinand Denis para a compreensão das primeiras idéias românticonacionalistas propagadas pela então nascente literatura brasileira, deve-se evidenciar a obra que melhor o caracterizou neste papel. Em outras palavras, é a princípio a que melhor pode informar sobre o caráter de seu pensamento referente ao tema em questão. Tratase do seu Résumé de l'Histoire Littéraire du Brésil, publicado em 1826 como uma espécie de apêndice do Résumé de l'Histoire Littéraire du Portugal.

À primeira vista, pode-se dizer que no Résumé o francês insistirá no desenvolvimento de um ponto de vista caro a iluministas como Montesquieu - crente na determinação da natureza sobre o progresso e sobre o estilo das artes. Entretanto, nota-se de forma determinante uma relação com a necessidade de serem buscadas, através de uma literatura "com os olhos nos caracteres populares", as raízes da nação. Como fontes genuínas primitivas, essas raízes dariam forma ao Gênio Nacional do novo país recém-independente tendo por base o seu povo descrito como "jovem e enérgico", reconhecido em sua individualidade. Nesse aspecto, convém dizer que em nenhum livro, antes deste, o complexo - tão presente em Chateaubriand e Bernardin de Saint-Pierre, unindo homem mestiço, vida rústica, floresta virgem e campos ilimitados - foi tão marcante para a imaginação do leitor brasileiro. ${ }^{10}$

Como uma primeira consideração sobre o texto em foco, é preciso reiterar o seu caráter pedagógico. De fato, o francês Ferdinand Denis se coloca de maneira eloqüente como um guia, uma autoridade apta a indicar o caminho pelo qual a poesia brasileira deveria seguir ou o caráter que deveria assumir. ${ }^{11}$ Suas concepções, é sempre bom destacar, se expandiram então rapidamente, determinando pontos de vista e fundando obras. Vale mencionar que sua visão gerou influências na poesia, no romance e no teatro,

${ }^{10}$ Cf. DENIS, 1826. In: CESAR, 1978. p.29.

${ }^{11}$ DENIS, 1826. In: CESAR, 1978. p.35. 
instaurando assim o ambiente para o surgimento das primeiras obras românticas no Brasil.

Com efeito, Denis é explícito não somente em seu didatismo, como também na determinação dos espaços de poder político e cultural. Seu texto está na primeira pessoa do plural, frisando um nós - o ponto de vista do europeu - diante dos outros, os americanos, os habitantes do vasto, inóspito e fascinante Novo Mundo:

Não estamos mais na época em que se podiam manter os americanos em sujeição, por meio dos laços políticos e da ignorância. Nos lugares de onde extraímos ouro, deixamos escapulir o germe de todos os conhecimentos. ${ }^{12}$

Percebe-se de forma bem ilustrativa o tom civilizador do autor, uma característica que se manterá sob vários preceitos. Aqui, indicase a Europa - com a óbvia inclusão de Portugal - a "deixar escapulir" o germe de todos os conhecimentos em uma terra que parece sedenta. A pregação indianista sugerindo a independência do pensamento se inicia quando Denis afirma que os homens do Novo Mundo, "seduzidos por um ambiente delicioso, dominados por paixões nobres e ardentes”, experimentam já a necessidade de ir buscar inspirações poéticas em uma fonte que verdadeiramente lhes pertença. ${ }^{13}$

Em contraste com o europeu, agente transformador da natureza, o "povo americano" sob o domínio do meio haveria de honrar as suas tradições nativistas em coerência com o que deveriam ser as suas aspirações. Com a terra brasileira em foco, Denis declara:

O Brasil, que sentiu necessidade de adotar instituições diferentes das que lhe haviam sido impostas pela Europa, já sente necessidade de haurir inspirações poéticas numa fonte que lhe pertença de fato; e, na sua glória nascente, bem cedo nos dará obras-primas deste primeiro entusiasmo, que atesta a juventude de um povo. Se essa parte da América adotou uma língua que a nossa velha Europa

12 DENIS, 1826. In: CESAR, 1978. p.35.

${ }^{13}$ DENIS, 1826. In: CESAR, 1978. p.36. 
aperfeiçoara, deve rejeitar as idéias mitológicas devidas às fábulas da Grécia: usadas por nossa longa civilização, foram dirigidas a extremos onde as nações não as podiam bem compreender e onde deveriam ser sempre desconhecidas; não se harmonizam, não estão de acordo nem com o clima, nem com a natureza, nem com as tradições. A América, estuante de juventude, deve ter pensamentos novos e enérgicos como ela mesma; nossa glória literária não pode sempre iluminá-la com um foco que se enfraquece ao atravessar os mares, e destinado a apagar-se completamente diante das aspirações primitivas de uma nação cheia de energia. ${ }^{14}$

Este trecho do estudo de Denis é extremamente rico em elucidações sobre a dimensão cultural de suas idéias. Nota-se uma ênfase à busca pela diferença cultural no Brasil, com o fim de que essa terra se mantivesse fiel a suas inspirações e instituições, em harmonia com um povo jovem. O estudioso francês evidencia assim o seu gosto popular e coloca diante da jovem América o exemplo da velha Europa de longa civilização, a aperfeiçoar línguas que seriam adotadas pela América, o que conformaria uma produtiva e paradigmática tutela. As noções mitológicas foram deslocadas de forma equivocada para nações incapazes de bem as assimilar, uma vez que, segundo o determinismo do autor, estão em desacordo com o clima, com a natureza e com as tradições desses povos. Para estes cabia o papel renovador e "energético", celebrando uma diferença primitiva, porém sem que se perca de vista o modelo europeu.

Denis parece evidenciar a dificuldade do Brasil, "seduzido e dominado pelo ambiente", de suplantar essas limitações e então "compreender" as idéias mitológicas da Grécia que fundam o pensamento moderno ocidental. De forma contrária, sendo jovem e promissor, o novo território deve buscar luz própria segundo suas aspirações primitivas, algo de acordo com a suas tradições e não como imposição da metrópole colonizadora. Observa-se que a nação é colocada como jovem e "cheia de energia" devido certamente ao curto caminho trilhado dentro da civilização nos

${ }^{14}$ DENIS, 1826. In: CESAR, 1978. p.36. 
moldes europeus. A Europa, na medida em que soube adquirir experiência e evolução conforme a sua "longa civilização", mostrase na citação como em franca maturidade, colocando-se apenas na posição de interessada espectadora do espetáculo proporcionado pelo novo.

Para essa nação de povo entusiasmado e ainda adolescente consoante os parâmetros ditados pelo pai do nacionalismo literário no Brasil, "o pensamento deve alargar-se como o espetáculo que se lhe oferece", "não procurando outro guia que a observação". ${ }^{15}$ Tal preceito, sendo respeitado, poderia com efeito gerar no Brasil uma espécie de literato-naturalista, mais descritivo e imaginoso e menos reflexivo. Considerando-se que o Brasil aos olhos da Europa não teria existido evidentemente antes do descobrimento português, sua Idade Média - ou o período que melhor fundamentasse a sua diferenciação étno-histórica - estaria nos séculos em que a "grandeza selvagem", tanto do índio quanto do primeiro colono, freqüentou livremente o território:

O Novo Mundo não poderá passar sem tradições respeitáveis; dentro de alguns séculos, a época presente, na qual se fundou a sua independência, nele despertará nobres e comovedoras evocações. A sua idade das fábulas misteriosas e poéticas serão os séculos em que viveram os povos que exterminamos e que nos surpreendem por sua coragem, e que retemperaram talvez as nações saídas do Velho Mundo: a recordação de sua grandeza selvagem cumulará a alma de orgulho, suas crenças religiosas animarão os desertos; os cantos poéticos, conservados por algumas nações, embelezarão as florestas. O maravilhoso, tão necessário à poesia, encontrar-se-á nos antigos costumes desses povos, como na força incompreensível de uma natureza constantemente mutável em seus fenômenos. ${ }^{16}$

É interessante perceber que a teoria indianista de Denis permite a expressão de um contraditório mea culpa. Logo, os povos ancestrais do Novo Mundo são aqueles "que exterminamos", ou seja,

${ }^{15}$ DENIS, 1826. In: CESAR, 1978. p.36.

${ }^{16}$ DENIS, 1826. In: CESAR, 1978. p.36. 
destruíram-se aqueles que não foram aculturados. Na caracterização do indianismo literário, deve-se salientar nas narrativas o índio ideal, o "cavaleiro medieval do Novo Mundo" nas palavras de Antonio Candido, de coragem surpreendente, útil à poesia tradicional por ser maravilhoso, manipulável segundo sonhos e aspirações, um artifício enfaticamente literário. Convém deduzir a partir daí que o francês na realidade apenas simula reconhecer a diferença da ex-colônia. De fato, segundo suas palavras o Novo Mundo deverá manter as "tradições respeitáveis", ou melhor, os costumes e os hábitos do Velho Mundo - incluindo-se aí os da ex-metrópole portuguesa - relacionados à exaltação de um passado maravilhoso que deve ser revivido em fábulas misteriosas e poéticas. Vê-se assim que, apesar da mudança dos componentes, o padrão é mantido.

Denis parece, em determinados momentos, hesitar em seu posicionamento frente às benesses da civilização moderna. É algo até certo ponto compreensível em seu direcionamento iluminista - por ser crente no poder das luzes do progresso e da civilização -, e romântico rousseauísta - compreendendo os males da civilização e da modernidade:

Estudados que sejam os leves vestígios remanescentes de três séculos de destruição, aí se acharão todos os pensamentos primitivos que excitam fortemente a imaginação; mas, para que se nos deparem tais pensamentos em toda a sua energia, não será preciso buscá-los às hordas que a civilização destruiu lentamente, as quais ocultam as desgraças da raça americana nas plagas em que foram confinadas; e penetrando-se no seio das florestas, interrogando-se as nações livres, ver-se-ão os campos ainda vivificados por pensamentos verdadeiramente poéticos. ${ }^{17}$

A fim de agudizar a importância do elemento nativista, indicando a supremacia do aspecto primitivista como caracterizador do Gênio Nacional brasileiro, o francês chega a comparar a natureza européia "clássica" com a "romântica" natureza americana:

${ }^{17}$ DENIS, 1826. In: CESAR, 1978. p.37. 
Que se pretende venha o americano a fazer de nossas comparações, sugeridas por uma natureza já esgotada pelo trabalho de séculos? (...) A aurora da Grécia, com seus róseos dedos, abrirá aquele céu ofuscante de esplendor, cujo brilho faria empalidecer o mesmo Apolo? Se os poetas dessas regiões fitarem a natureza, se se penetrarem da grandeza que ela oferece, dentro de poucos anos serão iguais a nós, talvez nossos mestres. ${ }^{18}$

Verifica-se aí novamente a frustrada ambição de Denis tendo em vista o desejo de reconhecer a alteridade da nova nação. O autor lembra a influência da natureza - que poderia gerar variações culturais e outros homens conforme a receita de Montesquieu. Entretanto, ele acaba por afirmar que "os poetas dessas regiões" poderiam, se seguirem seu conselho, ser "iguais a nós, talvez nossos mestres". Denis assim parece compreender o fenômeno da cultura de uma forma unidimensionada, de acordo com um pensamento ainda centrado e homogeneizador. Vê-se que ele também se retrata como "prisioneiro do pitoresco" como bem expressou Guilhermino César. ${ }^{19}$

Mais tarde, demonstrando novamente seu hesitante e paradoxal ponto de vista concernente aos possíveis benefícios trazidos pela civilização européia ao Novo Mundo, Denis tira da memória os já mencionados "três séculos de destruição" e contraditoriamente declara:

Não temo dizê-lo, o americano, no qual tantas raças se misturam, o americano, orgulhoso de sua terra, de sua riqueza, de suas instituições, virá um dia visitar a Europa, assim como dirigimos nossos passos na direção das ruínas do antigo Egito. Pedirá então lembranças poéticas a esta terra que brilhara com tamanho fulgor; pagar-lhe-á justo tributo de reconhecimento. A Europa fundamentou a grandeza do Novo Mundo, e este será talvez, um dia, o seu mais belo título de glória. ${ }^{20}$

\footnotetext{
${ }^{18}$ DENIS, 1826. In: CESAR, 1978. p.37.

${ }^{19}$ CESAR, 1978. p.31.

${ }^{20}$ DENIS, 1826. In: CESAR, 1978. p.38.
} 
Nesse trecho, observa-se então um impulso de cobrança por parte do europeu: ele há de ser sempre reconhecido como o responsável pela "fundamentação da grandeza do Novo Mundo". Tal grandeza seria erigida dados os resultados do processo colonizador empreendido por Portugal, que teria sido capaz de tornar o americano portador de riquezas e orgulhoso de sua terra, de suas instituições e do fato de ser fruto de um cruzamento de raças.

Com efeito, é indispensável mencionar que, ao lado da fascinação pelo pitoresco e pela possibilidade de moldá-lo segundo os interesses de estabelecer a partir dele as bases de uma (como se viu) difícil alteridade, Denis logrou abrir as portas para uma perspectiva de alteridade de fato no Brasil. Isso apenas foi possível quando ele foi levado a exaltar a profunda miscigenação já presente nas terras brasileiras do início do séc. XIX, que acabou por proporcionar ao Brasil um desvio da linha consagrada pelo modelo europeu.

Em um longo trecho de seu estudo, o autor indica o cruzamento de raças como traço enriquecedor da cultura americana, salientando as contribuições que cada raça haveria de trazer para a formação da miscigenada nação brasileira. Como exemplos ilustrativos, o americano é indicado como "sonhador":

...se fala, é em voz baixa, com um acento lastimoso nas palavras; raramente se anima, retendo a energia no fundo da alma, que é toda pela independência, pela liberdade que reina nas florestas. O negro necessita abandonar-se ao calor de sua imaginação, e precisamos acompanhar-lhe o pensamento; a rapidez de suas palavras não the basta à abundância das idéias; (...) inconstante nos sentimentos, mas sempre crédulo, o sobrenatural embeleza-lhe as narrativas (...); e o branco, que partilha amiúde o trabalho daqueles dois homens, orgulhoso de pertencer à raça dos dominadores, cria-se tradições novas, mas retém as dos velhos tempos. ${ }^{21}$

Sobre os devidos cruzamentos:

${ }^{21}$ DENIS, 1826. In: CESAR, 1978. p.39. 
Quer descenda do europeu, quer esteja ligado ao negro ou ao primitivo habitante da América, o brasileiro tem disposições naturais para receber impressões profundas. (...) O filho de mãe indígena possui não sei que impulso de independência, que o leva a sentir a necessidade de exaltar, antes de tudo, a sua pátria; busca aventuras no meio da floresta; tem a perseverança do branco e a coragem do homem acobreado: sua alma é enérgica e seu espírito melancólico; desta raça sairão grandes coisas. (...) O filho de pai europeu e mãe negra, o mulato, recorda o árabe nos traços, na cor e no caráter: o amor, exaltando-lhe a alma, torna-o entusiasta; (...) pensa com rapidez, tem a imaginação colorida, o coração arrebatado. É poeta, tal como a natureza o criou. ${ }^{22}$

Vê-se que o francês aponta os traços físicos e psicológicos do mameluco e do mulato, esquecendo-se do cafuzo. Nessa perspectiva, imagina-se que esse elemento talvez tenha sido prejudicado pela ausência do sangue branco, aquele que pertenceria aos empreendedores, à "raça dos dominadores" como o autor diz. Da mesma forma a figura paterna é identificada, nos cruzamentos raciais, sempre como o europeu, o que poderia corroborar o seu poder de controle e de dominação passível de ser exercitado até mesmo sobre o corpo da mulher índia e/ou negra. Todavia, apesar de tal etnocentrismo, notase que o autor reconhece a miscigenação e, diferentemente de muitos europeus que poderiam ver nisso um aspecto inferior, ele a exalta como um traço que caracteriza e enriquece o "americano", ou antes, o brasileiro. Conforma-se assim uma situação em que enfim a excolônia poderia encontrar uma identidade específica, mesmo que ainda puramente racial. ${ }^{23}$

Demonstrando consciência de seu papel influente sobre os literatos brasileiros do romantismo, o estudioso chega então a fazer afirmações de grande contundência. Desse modo, ele salienta a

${ }^{22}$ DENIS, 1826. In: CESAR, 1978. p.40.

${ }^{23}$ Pode-se pensar que com o fim do séc. XIX e início do séc. XX, o país logrou assumir também um pensamento "crivado de raças", algo coerente com um ideal de fato "antropofágico" onde culturas e idéias são assimiladas e redimensionadas. 
capacidade da literatura francesa em tutelar, seja provocando,- seja modificando - a produção literária no Brasil:

O papel que nos cabe desempenhar nesse país é ainda muito significativo, e se os ingleses têm, mais do que nós, a influência comercial que em toda a parte lhes caracteriza a atividade, devemos contentar-nos com ver uma nação esplendente de juventude e de engenho afeiçoar-se às nossas produções literárias, por causa destas modificar suas próprias produções, e estreitar através dos liames espirituais os que devem existir na ordem política. ${ }^{24}$

Tal trecho é realmente muito revelador. Após instaurar e afirmar todo um pensamento de independência da ex-colônia em relação à Portugal, Denis então situa a França no papel de país gerador de influência. Nesse ponto de vista, percebe-se que a determinação européia se mantém, uma vez que é estabelecida apenas uma substituição de países ascendentes. Nota-se que Denis destaca ainda a necessidade de estreitamento dos laços também na ordem política, o que pode caracterizar um desejo "francês" de estar presente mesmo no momento em que a ex-colônia procurasse uma melhor organização nacional e política.

Em sua "Visão sumária de alguns poetas dos séculos XVII e XVIII", o francês exalta aqueles que elaboram uma produção literária indianista coerente com o seu modelo de Gênio Nacional prescrito à literatura brasileira. São utilizados como exemplos, entre outros, Santa Rita Durão em seu poema épico Caramuru e Basílio da Gama em $O$ Uraguai. O primeiro, detidamente estudado, foi considerado "excelente pintura do espírito inflamado e aventuroso dos portugueses daquela época, em oposição à simplicidade selvagem de um povo ainda na infância", além de que "é nacional e indica bem o alvo a que se deve dirigir a poesia americana". ${ }^{25} \mathrm{O}$ Uraguai, por seu lado, seria visto como "curiosa análise de caracteres e animada pintura das paixões daqueles homens, tão diversos no concernente aos hábitos e costumes". ${ }^{26}$

${ }^{24}$ DENIS, 1826. In: CESAR, 1978. p.41.

${ }^{25}$ DENIS, 1826. In: CESAR, 1978. p.47.

${ }^{26}$ DENIS, 1826. In: CESAR, 1978. p.58. 
Consoante o pensamento de Denis a literatura indianista no Brasil, ao pintar "regiões estranhas, tão interessantes para os europeus", ${ }^{27}$ seria relevante também na afirmação da moral e dos valores dos povos civilizados. Essa moral e esses valores, prestigiosos na medida em que são assim difundidos, seriam na verdade convenientes tendo em vista a educação de um povo "selvagem e inocente como uma criança" como teria sido indicado o indígena. De forma elucidativa, pode-se mencionar o Caramuru, em que Denis vê o personagem Diogo, o europeu, espalhando as luzes da religião entre os selvagens, ${ }^{28}$ algo já apresentado em episódios da narrativa de Chateaubriand, Atala.

Nesse ponto de vista, Tomás Antônio Gonzaga, por empregar metáforas sugeridas pela mitologia, ${ }^{29}$ e Cláudio Manoel da Costa, "por ter se tornado demasiado europeu nas suas metáforas", ${ }^{30}$ seriam condenáveis por desrespeitar a cor local e seguir uma deslocada moda clássica européia.

\section{Uma conveniente tutela francesa}

Denis se firma dessa maneira como um dos dínamos principais na expressão de um pensamento e de uma literatura brasileiros. Sob esse prisma, ele conseguiu ser visto não como estrangeiro à pátria, mas como franco-brasileiro, "divulgador das coisas do Brasil" e "autoridade em matéria de Brasil". Suas noções, palavras ou mesmo a simples menção ao seu nome tornaram-se constantes nas obras de historiadores de épocas diversas, de romancistas e de poetas, de

\footnotetext{
${ }^{27}$ DENIS, 1826. In: CESAR, 1978. p.73.

${ }^{28}$ DENIS, 1826. In: CESAR, 1978. p. 50.

${ }^{29}$ DENIS, 1826. In: CESAR, 1978. p.66.

${ }^{30}$ DENIS, 1826. In: CESAR, 1978. p.69.
} 
etnólogos ou de antropólogos, bastando para isso lembrar que ainda em estudos realizados neste século ele está presente. ${ }^{31}$

Nota-se que, com a colaboração de literatos brasileiros, Denis na época mantinha-se informado sobre tudo que lhe interessava, ao mesmo tempo em que continuava a irradiar as luzes do seu saber. Ele exerceu de forma competente o papel de mediador das noções que circulavam entre o Brasil e a França, principalmente na medida em que se apresentava continuamente como voz imperiosa, consciente de sua autoridade e atualizada sobre qualquer informação sobre o país. ${ }^{32}$

Revelando-se um "romântico iluminista" portador de uma erudição enciclopédica, Denis se apresentava como apto a conduzir o processo "civilizacional" brasileiro, o que o fez se tornar fonte obrigatória de consulta. É preciso destacar bem que seu público seria composto então, entre outros, por brasileiros ávidos por conhecer o Brasil, a bem dizer, o afamado Brasil exótico e original tão celebrado pelos naturalistas. O francês seria visto assim como uma espécie de filtro enriquecedor, um representante da óptica européia que, no momento em que contemplasse a história, a geografia e a literatura de um país, tornaria-os dessa forma mais reais, mais interessantes, mais íntegros e independentes.

Além disso, e que talvez seja o mais importante, convém enfatizar a conveniência das interpretações de Denis para o processo

31 À guisa de exemplo, é possível citar (...) Ensaios e estudos (ed. de 1831), de Capistrano de Abreu; História do Brasil (1947), de Pedro Calmon; Teoria da história do Brasil (1949), de José Honório Rodrigues, para lembrar alguns historiadores. Além destes, cf. Casa grande e senzala (1934) ou Sobrados e mucambos (1936), de Gilberto Freyre; Introdução à arqueologia brasileira (1936), de Angyone Costa; (...); O indio brasileiro e a Revolução Francesa (1937), de Afonso Arinos, (...) entre outros tantos. Cf. ROUANET, 1991. p.140. 32 "Não havia publicação que não lhe fosse enviada (...), nem acontecimentos que não lhe fossem relatados nos mínimos detalhes (...). Dele serviam-se os brasileiros para obter referências, indicações, publicações que lhes interessassem, e mesmo favores diversos". ROUANET, 1991. p.152. 
de constituição nacional do país. De fato, os escritores brasileiros nacionalistas se mostraram grandemente interessados nas noções divulgadas por esse francês, todas aptas a garantir a diferença nacional diante do repudiado modelo português, mesmo para uma terra de incipiente consciência do que seriam suas tradições, sua história e sua cultura. É portanto preponderante o instante em que o "simpático escritor francês" e "amigo do Brasil" estabelece as estruturas do indianismo tendo por base suas leituras do primeiro romantismo francês conforme as obras de Bernardin de Saint-Pierre - principalmente Paul et Virginie - e de Chateaubriand - em Atala sobretudo. Com efeito, é o conceito que lograria determinar os primeiros caminhos através dos quais o novo território tentaria enfim formular um rosto, uma identidade, uma realidade mesmo que imaginária. Com a pretensão de buscar primordialmente a compreensão do europeu diante das sociedades tropicais, Denis parece ver nestas uma poesia a expressar uma primitiva nostalgia, algo que um alemão como Herder soube bem salientar ao dizer que "a linguagem poética, que é de todos, é a 'língua-mãe da humanidade' e aparece, em sua pureza original e sua força, nos períodos primitivos de cada nação". ${ }^{33}$

\section{Uma alteridade postergada}

Percebe-se assim que Ferdinand Denis elaborou uma oportuna transposição de matrizes. Com o fim de manter a presença prescritiva da Europa no interessante Novo Mundo, ele houve por bem estabelecer um ambiente de repulsa contra a ex-metrópole, logrando assim um certo espaço para uma melhor atuação francesa. Conforme esse raciocínio, vê-se que a França parece ser indicada como mais apta devido ao fato de se revelar mais moderna, de cultura mais enobrecedora, sendo então mais digna de ser analisada, debatida e imitada. Nessa perspectiva, a alteridade pretendida pela ex-colônia seria novamente postergada diante da necessidade de aí

${ }^{33}$ Cf. FALBEL. In: GUINSBURG, 1993. p.43. 
se manter a existência de um laboratório para as experimentações culturais e poéticas do Velho Mundo.

O sonho nacional brasileiro, de fato, precisava ainda estabelecer uma estratégia de sobrevivência em meio às outras nações. Torna-se dessa forma cada vez mais indispensável sorver deliberadamente as teorias dos grupos hegemônicos, sendo Portugal ou França, para melhor submetê-las à história nacional.

\section{Referências Bibliográficas}

CANDIDO, Antonio. Formação da Literatura Brasileira. 2 v. 7.ed. Belo Horizonte: Itatiaia, 1993.

CANDIDO, Antonio. Sílvio Romero: teoria, crítica e bistória literária. Rio de Janeiro: Livros Técnicos e Científicos; São Paulo: Edusp, 1978.

CANDIDO, Antonio. Literatura e sociedade. São Paulo: Cia. Edit. Nacional, 1976.

DENIS, Jean Ferdinand. Résumé de l'bistoire littéraire du Portugal, suivi du résumé de l'bistoire littéraire du Brésil. 1826. In: CESAR, Guilhermino (Org.). Historiadores e críticos do romantismo 1: a contribuição européia, crítica e história literária. Rio de Janeiro: Livros Técnicos e Científicos, 1978.

GUINSBURG, J. (Org.). O romantismo. São Paulo: Perspectiva, 1993.

LIMA, Luiz Costa. Sociedade e discurso ficcional. Rio de Janeiro: Guanabara, 1986.

LOWY, Michael \& SAYRE, Robert. Revolta e melancolia: o romantismo na contramão da modernidade. Trad. Guilherme F. Teixeira. Petrópolis: Vozes, 1995.

ROUANET, Maria Helena. Eternamente em berço esplêndido: a fundação de uma literatura nacional. São Paulo: Siciliano, 1991. SILVA, J. N. de Sousa. Bosquejo da história da poesia brasileira. Ed., apres. e notas José Américo Miranda. Belo Horizonte: Ed. UFMG, 1997. 


\section{Resumo}

Este trabalho pretende discutir as relações entre literatura e nacionalismo, tendo em vista o séc. XIX em que a literatura brasileira parece ter substituído Portugal pela França no papel de país influente no que concerne às opções relacionadas à formação nacional e cultural.

\section{Abstract}

This work intends to discuss the relationship between Literature and Nationalism, having as reference the nineteenth century when Brazilian literature seems to substitute Portugal for France as the country that shows the way to be followed for being recognized in fact as national or autonomous. 